\title{
One step synthesis of core@shell SiGe@Si nanoparticles and their use as active material in high capacity anodes for Li-ion batteries
}

\author{
Antoine Desrues ${ }^{1}$, John P. Alper ${ }^{1,2}$, Florent Boismain ${ }^{1}$, Pierre-Eugène Coulon ${ }^{3}$, Adrien Soloy ${ }^{1}$, Cédric Haon $^{2}$, Nathalie \\ Herlin-Boime $^{1}$ \\ 1 NIMBE, UMR 3685 CEA, CNRS, Université Paris-Saclay, CEA-Saclay, F-91191 Gif-sur-Yvette Cedex
2 Université Grenoble Alpes, CEA-Liten, F-38054 Grenoble, France
3 LSI, CNRS, CEA-DRF-IRAMIS, Ecole Polytechnique, Université Paris-Saclay, Palaiseau, France
}

In the frame of energy transition, silicon is a material of interest to develop Li-ion batteries with increased energy density. Nevertheless, the important volume change upon cycling $(280 \%)$ and reactivity towards electrolytes lead to rapid degradation of performances. Designing silicon-germanium structures is an efficient strategy to obtain stable performances of Li-ion batteries anodes. The synergetic effect of alloying silicon and germanium was demonstrated by Duveau et al [1], using micrometric particles obtained by ball-milling. The stability of the alloys was better than the stability of pure silicon and its capacity was higher than the capacity of pure germanium.

This paper presents the one step synthesis of nanoparticles of Si-Ge alloys by laser pyrolysis using silane and germane as gaseous precursors. The average chemical composition of the powders ( $\mathrm{Si} / \mathrm{Ge}$ ratio) appears well correlated with the silane to germane ratio introduced in the reactor. Using STEM-EDX, an original SiGe@Si core@shell heterostructure is observed on these particles (fig. 1); the alloy is surrounded by a silicon shell. Using in-situ temperature measurements, we found that the temperature in the reaction zone is above the stability zone of the alloy and favors migration of chemical species to the surface. Varying the ratio between precursor gases led to the synthesis of various $\mathrm{Si}_{100-\mathrm{x}} \mathrm{Ge}_{\mathrm{x}}$ heterostructures with $\mathrm{x}=$ $0,20,47,77$, and 100. X-Ray diffractions studies enlightened the proportions of each phase and their compositions, in good correlation with EDX measurements.

All the three alloy compositions were cycled at $\mathrm{C} / 5$ in coin cells vs lithium. The electrochemical performances (fig. 2) outperform materials with similar compositions already published [1]. The capacity of all alloy compositions is higher when compared to germanium, whereas stability and coulombic efficiency upon cycling is better when compared to silicon. The best performances were obtained for $\mathrm{Si}_{53} \mathrm{Ge}_{47}$ with a reversible capacity of $1685 \mathrm{mAh} \cdot \mathrm{g}^{-1}$ after 60 cycles.

[1] Duveau, D. et al., Chemistry of Materials 2015, 27 (9), 3226-3233

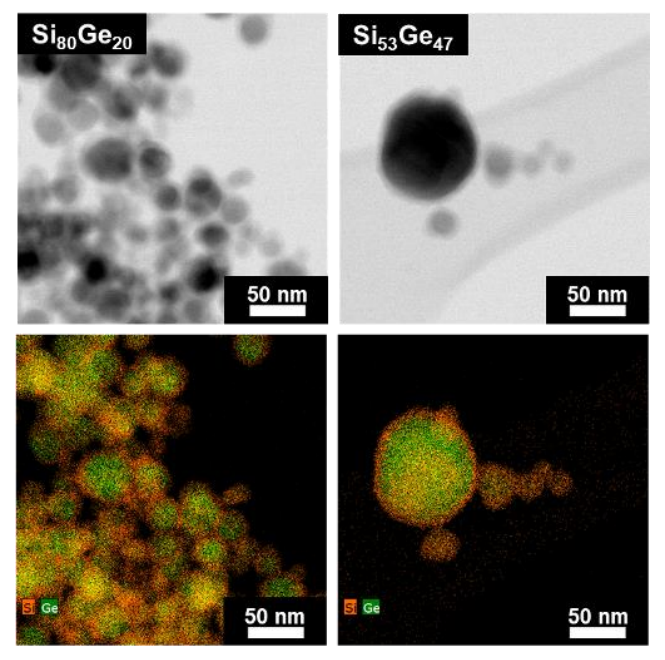

Figure 1: STEM and STEM-EDX pictures of two $\mathrm{Si}_{\mathrm{x}} \mathrm{Ge}_{1-\mathrm{x}}$ alloys: $\mathrm{Si}_{80} \mathrm{Ge}_{20}$ (left column), $\mathrm{Si}_{53} \mathrm{Ge}_{47}$ (right column), green color corresponds to Ge atoms while orange color corresponds to silicon. 
(a)

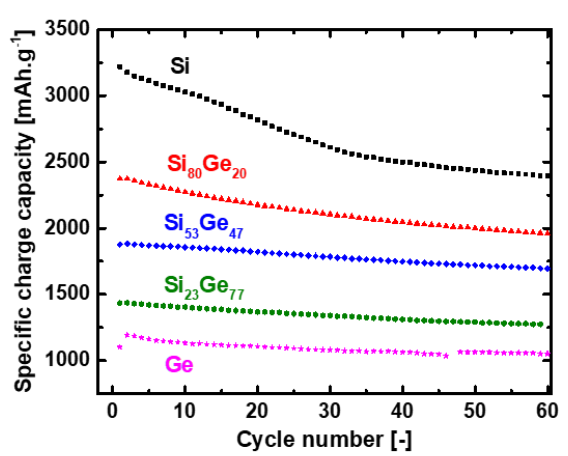

(b)

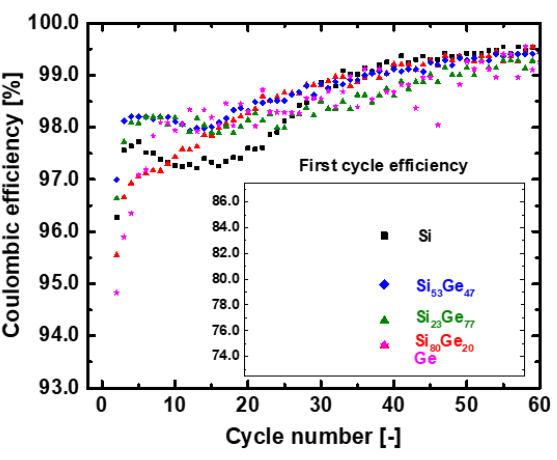

Figure 2: (a) Galvanostatic cycling performances of the alloys compared to silicon and germanium. (b) coulombic efficiencies of mentioned materials. 